\title{
On the Aramaic Onomasticon in the Cuneiform Text Corpus
}

Most of the Aramaic onomasticon is not located in extant alphabetic sources, but instead can be found in cuneiform sources. In order to learn more about the reach of Aramaic through the individuals using it as a spoken language during the first half of the first millennium BCE, we must attend to the Aramaic personal names that appear in this much larger corpus of texts and inscriptions. Using a method that considers both linguistic and conceptual criteria, this paper compiles and analyzes possible Aramaic names that appear in the cuneiform text corpus and culminates with an updated list of the genuine Aramaic onomasticon. Ultimately, this paper provides insight that may be used in identifying West Semitic and other foreign onomastica in the cuneiform text corpus. My talk presents the results of this paper, which emerges from a much larger study of Aramaic names in the first millennium BCE. 